\title{
Diagnostic tools of caprine and ovine anaplasmosis: a direct comparative study
}

\author{
I. I. Shabana ${ }^{1,2^{*}}$ D, N. M. Alhadlag ${ }^{1}$ and H. Zaraket $^{3,4}$
}

\begin{abstract}
Background: The diagnosis of anaplasmosis is rather conflicting with other haemoprotozoans. Hence, the study aimed to compare and evaluate the efficiency of competitive ELISA (cELISA), indirect fluorescence antibody (IFA), and Polymerase chain reaction (PCR) for precise diagnosis of Anaplasma spp. and to assess their concordance with microscopic examination (ME).

Results: A total of 312 blood samples (189 sheep and 123 goats) were examined for Anaplasma infection during a 1 year period. Giemsa-stained blood smears were examined under the microscope. IFA and cELISA were used for the detection of Anaplasma spp. antibodies. PCR was used as a standard of truth and for the identification of Anaplasma species. Using CELISA assay, 47.4\% (148) were positive (93 sheep and 55 goats) with a sensitivity and specificity of 91.9 , and $86.9 \%$, respectively. Using IFA, it was found that $57.4 \%$ (179) were positive (113 sheep and 66 goats) with a sensitivity and specificity of 100 , and $93.3 \%$, respectively. PCR assay identified A. ovis in 49 (25.3\%) sheep and 30 (15.5\%) goats, and A. phagocytophilumin 74 (38.1\%) sheep and 41 (20.8\%) goats.

Conclusions: High sensitivity and specificity values of IFA and ELISA tests compared to microscopic examination strongly support their utility in the diagnosis of Anaplasma infection. PCR was a more specific diagnostic tool that allows to discriminate between Anaplasma subspecies, which makes it the method of choice for anaplasmosis diagnosis.
\end{abstract}

\section{Background}

Anaplasma are obligate intracellular, Gram-negative, tick-borne rickettsial bacteria that are important animal and human pathogens. Anaplasmosis constitutes a burden to livestock health and production in tropical and sub-tropical regions. It results in great economic losses due to decreased production, mortality, and lowered work efficiency of affected animals [7, 26].There are six recognized Anaplasma species: $A$. ovis, A. marginale, A. centrale, A. platys, A. bovis, and A. phagocytophilum [48]. A. ovis primarily infects sheep and goats, causing ovine and caprine anaplasmosis, respectively [24]. A. ovis infection is generally a subclinical or mild condition, while severe infection may involve anemia, abortion, and mortality [43].

\footnotetext{
* Correspondence: imanibrahim50@yahoo.com

${ }^{1}$ Biology Department, Faculty of Science, Taibah University, Al- madinah

Al-munawarah, Saudi Arabia

${ }^{2}$ Faculty of Veterinary Medicine, Department of Bacteriology, Immunology

and Mycology, Suez Canal University, Ismailia, Egypt

Full list of author information is available at the end of the article
}

A. phagocytophilum infects humans and animals and is thought to be zoonotic $[38,49]$. The disease is known as tick-borne fever (TBF) in human and ruminants granulocytic anaplasmosis (HGA) in human. Tick-borne fever is characterized by high fever, which may last for one to 2 weeks, followed by a severe neutropenia, which makes the animals susceptible to secondary infections $[39,40]$. Ruminants granulocytic anaplasmosis is characterized by fever, myalgia, chills, depression, and headache [47]. Anaplasmosis became a notifiable disease in 1999 [11, 20].

Anaplasmosis diagnosis is usually based on the microscopic examination (ME) of Giemsa-stained blood smears, serological, and molecular diagnostic procedures. Microscopic diagnosis may be difficult in carrier animals, thus various serological techniques have been used for the detection of Anaplasma-specific antibodies such as indirect immunofluorescence antibody (IFA), enzyme-linked immunosorbent assay (ELISA), and complement fixation tests (CF) $[9,23]$.The competitive

(C) The Author(s). 2018 Open Access This article is distributed under the terms of the Creative Commons Attribution 4.0 International License (http://creativecommons.org/licenses/by/4.0/), which permits unrestricted use, distribution, and 


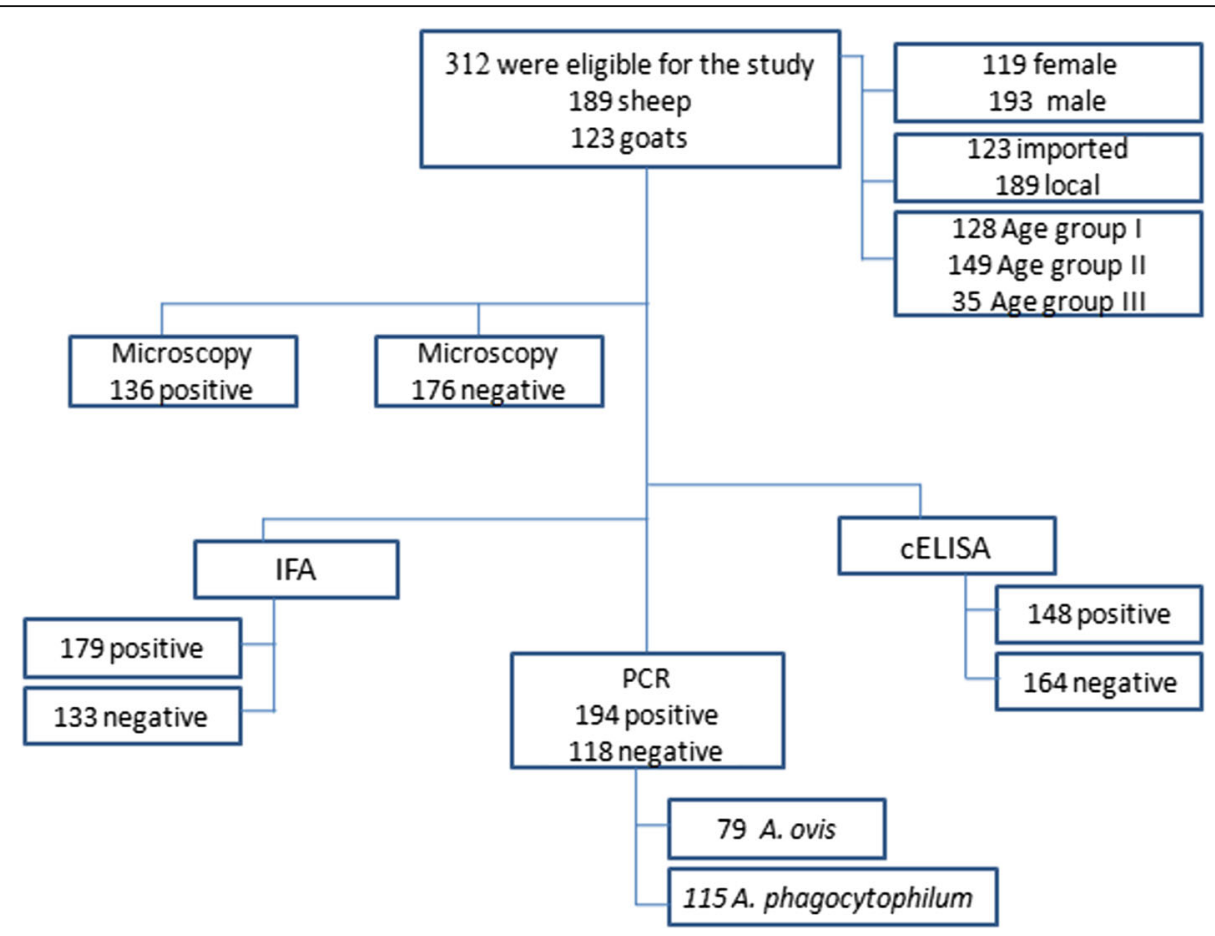

Fig. 1 Study flow chart

ELISA (cELISA) is depending on the use of a monoclonal antibody (Mab) ANAF16C1 that recognizes the conserved (MSP-5) antigen of different Anaplasma spp. [28, 46]. cELISA test has high sensitivity and specificity for detection of Anaplasma antibodies [27].

The "Gold standard" method for the diagnosis of Anaplasma spp. relies on the combination of the microscopic examination and cELISA [22].The indirect immunofluorescence antibody test is widely used for the diagnosis of blood protozoon and Rickettsia [25].The IFA test is commonly used in epidemiological studies because of its low costs $[14,25]$.

Molecular identification methods such as Polymerase chain reaction (PCR) have several advantages compared to the traditional serologic and blood smear tests [21]. PCR is the most sensitive and reliable diagnostic tool that allows discriminating between Anaplasma subspecies [44]. In addition, PCR can detect the coinfections with multiple Anaplamsa subspecies [5].

The aim of the study was to assess the sensitivity and specificity of the different diagnostic tools used for detecting anaplasmosis in sheep and goats.

\section{Methods}

\section{Study design}

This was a prospective study conducted according tothe Standards for Reporting Diagnosis Accuracy Studies (STARD) [13].

\section{Animals}

Blood samples were collected from sheep and goats from the local abattoir and different farms in Medina, Kingdom of Saudi Arabia (KSA). Eligibility criteria were suspicion of anaplasmosis among sheep and goats in Medina, which has a subtropical climate and borders on a fully tropical climate. The animals were surveyed for anaplasmosis from September 2011 to November 2012 (Fig. 1). Microscopic examination of blood smears was basically used as a reference diagnosis of anaplasmosis. cELISA and IFA are the most commonly used serological methods to detect antibodies against Anaplasma. PCR is the most reliable diagnosis of Anaplasma infection.

Table 1 Basic demographics of the sampled animals

\begin{tabular}{lll}
\hline Categories & & $N(\%)$ \\
\hline Gender & Female & $119(38.1 \%)$ \\
& Male & $193(61.9 \%)$ \\
Host & Sheep & $189(60.6 \%)$ \\
& Goat & $123(39.4 \%)$ \\
Source & Imported & $123(39.4 \%)$ \\
& Local & $189(60.6 \%)$ \\
Age & Age group I (2 m-2y) & $128(41.5 \%)$ \\
& Age group II (2y-4y) & $149(47 \%)$ \\
& Age group III (4y-6y) & $35(12 \%)$ \\
\hline
\end{tabular}




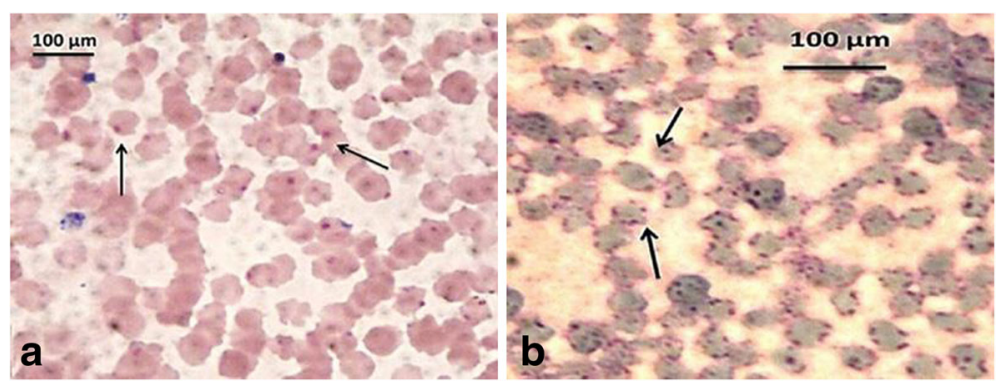

Fig. 2 a, b Anaplasma species under microscope appears as small and roughly spherical intraerythrocytic parasite measuring about 0.2 to $0.5 \mu$ m

\section{Blood samples collection}

A total of 312 blood samples were collected from 189 sheep and 123 goats of different age groups ( 2 months to 6 years) and sources (local and imported). The imported animals were either from Sudan, Pakistan, Australia, and Somalia. Venous blood samples were collected from each individual animal in two $4 \mathrm{ml}$ vacutainer tubes (BD vacutainer, BD-Plymouth, UK), one containing EDTA and one additive-free. To separate sera, the additive-free blood was allowed to clot for about 15-30 min at room temperature. The tubes then centrifuged at 1000-2000 rpm for $10 \mathrm{~min}$ and serum was collected. The serum specimens were stored at $-20^{\circ} \mathrm{C}$ for further use.

\section{Microscopic examination}

Thin blood smears were prepared for microscopic examination accordingly the standard protocol [7].The slides were allowed to air-dry before being fixed with absolute methanol. Fixed smears were stained with 10\% Giemsa (Cresent diagnostic, KSA) and examined by using compound microscope under oil immersion lens. About 25 fields were examined from each slide for the presence of Anaplasma and the number of infected erythrocytes. Anaplasma was identified on the basis of its morphology [8].

\section{Competitive ELISA (cELISA) assay}

Sera were screened for the presence of Anaplasma antibodies by using the VMRD cELISA kit (VMRD Inc., Pullman, WA, USA), according to the manufacturer instructions. The optical density (OD) was measured at $650 \mathrm{~nm}$ with an ELISA microplate reader MR-960 (perlong Medical Equipment Co., Ltd., China). The results were calculated according to the formula: 100 [1-(Sample OD $\div$ Negative Control OD)]. The positive sample OD must be $>30 \%$.

\section{Immunofluorescence (IFA)assay}

Sera were screened for Anaplasma immunoglobulin G (IgG) by a semi-quantitative indirect IFA commercial kit (Fuller, USA), according to the manufacturer instructions. Briefly, sera samples were diluted in phosphatebuffer saline (PBS) and $25 \mu$ l were transferred to the slide wells. The slides were incubated at $35{ }^{\circ} \mathrm{C}$ for 30 min then washed with PBS followed by distilled water to remove the unreacted antibodies. Twenty five $\mu \mathrm{l}$ antiovine conjugate with DyLight 488 dye (Fuller, USA) were added and incubated then removed by washing as previously described. The slide was examined by standard fluorescence microscopy (Olympus BX50, Japan) at 400X magnification, the positive reaction appears as green fluorescent small cocci with a red background.

\section{DNA extraction and PCR}

DNA extraction was carried out using the G-spinTM Total DNA Extraction Kit (iNtRON Biotechnology, Korea) according to the instructions of the manufacturer. PCR was performed to detect both Anaplasma phagocytophilum, Anaplasma ovis using BioinGentech Veterinary PCR Kits (Concepcion, Chile) according to the instructions of the manufacturer. The cycling conditions were initial denaturation at $94{ }^{\circ} \mathrm{C}$ for $2 \mathrm{~min}, 35$ cycles $\left(94^{\circ} \mathrm{C} 30 \mathrm{~s}, 57^{\circ} \mathrm{C} 30 \mathrm{~s}\right.$, $72{ }^{\circ} \mathrm{C} 30 \mathrm{sec}$ ) and a final extension at $72{ }^{\circ} \mathrm{C}$ for $5 \mathrm{~min}$.

Table 2 Microscopic examination

\begin{tabular}{llll}
\hline Host & \multicolumn{2}{l}{ Demographic factor } & $\begin{array}{l}\text { Positive animals } \\
\text { percentage }\end{array}$ \\
\hline Sheep $(n=189)$ & Gender & Male (128) & $66(34.9 \%)^{\mathrm{a}}$ \\
& & Female (61) & $20(10.6 \%)$ \\
& Age & Group I (84) & $47(24.9 \%)^{\mathrm{a}}$ \\
& & Group II (89) & $36(19.0 \%)$ \\
& & Group III (16) & $3(1.6 \%)$ \\
& Source & imported (82) & $53(28.1 \%)$ \\
& & Local (107) & $33(17.5 \%)$ \\
Goat $(n=123)$ & Gender & Male (65) & $38(30.9 \%)^{\mathrm{a}}$ \\
& & Female (58) & $12(9.8 \%)$ \\
& Age & Group I (44) & $22(17.9 \%)^{\mathrm{a}}$ \\
& & Group II (60) & $24(19.5 \%)$ \\
& & Group III (19) & $4(3.3 \%)$ \\
& Source & Imported (41) & $34(27.6 \%)$ \\
& & Local (82) & $16(13.0 \%)$ \\
\hline
\end{tabular}

Age group I ( 2 months to 2 years), group II ( $>2-4$ years), group III (> 4 - 6 years) ${ }^{\text {a }}$ Significant variation 
Table 3 Seroprevalence of anaplasma species among sheep and goats

\begin{tabular}{|c|c|c|c|c|c|c|c|c|}
\hline \multirow[t]{2}{*}{ Host } & \multirow{2}{*}{$\begin{array}{l}\text { Serological } \\
\text { assay }\end{array}$} & \multicolumn{2}{|l|}{ Gender } & \multicolumn{3}{|l|}{${ }^{* *} \mathrm{Age}$} & \multicolumn{2}{|l|}{ Source } \\
\hline & & Female & Male & Group I & Group II & Group III & Imported & Local \\
\hline \multirow[t]{2}{*}{ Sheep } & cELISA & 70 (37.0\%) & $23(12.2 \%)$ & $52(61.1 \%)$ & $39(43.8 \%)$ & $2(12.5 \%)$ & $59(71.1 \%)$ & $34(31.7 \%)$ \\
\hline & IFA & 82 (43.4\%) & 31 (16.4\%) & $60(31.7 \%)$ & $45(23.8 \%)$ & $8(4.2 \%)$ & 69 (36.5\%) & 44 (23.3\%) \\
\hline \multirow[t]{2}{*}{ Goat } & cELISA & $39(60.0 \%)^{*}$ & $16(27.6 \%)$ & $26(59.1 \%)$ & $25(41.7 \%)$ & 4 (21.1\%) & $36(87.8 \%)$ & 19 (23.1\%) \\
\hline & IFA & $45(36.6 \%)^{*}$ & $21(27.6 \%)$ & 30 (24.4\%) & 29 (23.6\%) & 7 (5.7\%) & 43 (34.9\%) & 23 (18.7\%) \\
\hline
\end{tabular}

* statistically significant $(P$-value is $<0.05)$

**statistically highly significant $(P$-value is $<0.01)$

\section{Statistical analysis}

Statistical analysis was performed using the Statistical Package for the Social Sciences version 20.0 (SPSS Inc. Chicago, USA). Eta-square and Chi-square were applied to compare the percentage of positive samples by each method. The differences were considered statistically significant when $P$-value is $<0.05$.

\section{Results}

The examined animals

A total of 189 (60.6\%) paired samples were collected from sheep and 123 (39.4\%) were obtained from goats. As shown in (Table 1), the animals were classified into three age groups: group I included samples collected from animals aged2 months to 2 years (128; 41.5\%), group II included animals $>2-4$ years $(149 ; 47 \%)$, and group III included animals $>4-6$ years $(35 ; 12 \%)$. According to the country of origin,189 (60.6\%) of the sampled animals were locally bred and included 107 (56.6\%) samples collected from sheep and 82 (43.4\%) samples of goats, and 123 (39.4\%) animals were imported including $82(66.7 \%)$ sheep and $41(33.3 \%)$ goats.

\section{Microscopic examination}

A total of 312 blood smears were examined for the presence of intra-erythrocytic inclusions using Giemsa stain. Anaplasma spp. appeared as small spherical deep purple intraerythrocytic inclusions, measuring about 0.2 to $0.5 \mu \mathrm{m}$ (Fig. 2a, b). Among the collected specimens, 130 were found positive with an overall prevalence of $43.6 \%$. Among the 130 positive animals, 86 (45.5\%)were sheep and 50 (40.7\%) were goat (Table 2). The difference in Anapalsma prevalence in sheep and goats was not significant $(P>0.05)$. The highest infection rate of Anaplasma spp. was among animals aged $2 \mathrm{~m}-2 \mathrm{y}$, in sheep $(47 / 86 ; 54.6 \%)$ and goats $(22 / 50 ; 44 \%)$ with a significant correlation $(P<0.05)$. The infection rate was higher albeit not significantly among the imported animals, $64.6 \%$ in sheep and $82.9 \%$ in goats compared to locally bred animals. Male animals had a higher and significant $(P<0.05)$ infection rate in sheep $(66 / 86 ; 76.7 \%)$ and goats $(38 / 50 ; 76 \%)$ compared to females.

\section{Competitive inhibition ELISA (cELISA) assay}

The overall prevalence of Anaplasma spp. using cELISA was $47.4 \%$ ( $n=148)$, including $93(49.2 \%)$ specimens from sheep and $55(44.7 \%)$ from goats. In sheep, the infection rates were higher among males (37\%), animals of the age group I (61.1\%). and imported animals (71.1\%). While in goats, the prevalence was $60 \%$ among males, $59.1 \%$ among age group I animals, and $87.8 \%$ in the imported animals (Table 3). Comparing the data obtained from microscopic examination with cELISA, it was observed that cELISA has high sensitivity (91.9\%) and specificity (86.9\%) than microscopic examination. The Gold standard of truth for the diagnosis of Anaplasma spp. relies on the combination of the microscopic examination and cELISA.

\section{Immunofluorescence (IFA)assay}

The presence of the intraerythrocytic Anaplasma spp. is indicated by greenish yellow or yellowish fluorescence (Fig. 3a, b). The overall prevalence of Anaplasma spp.

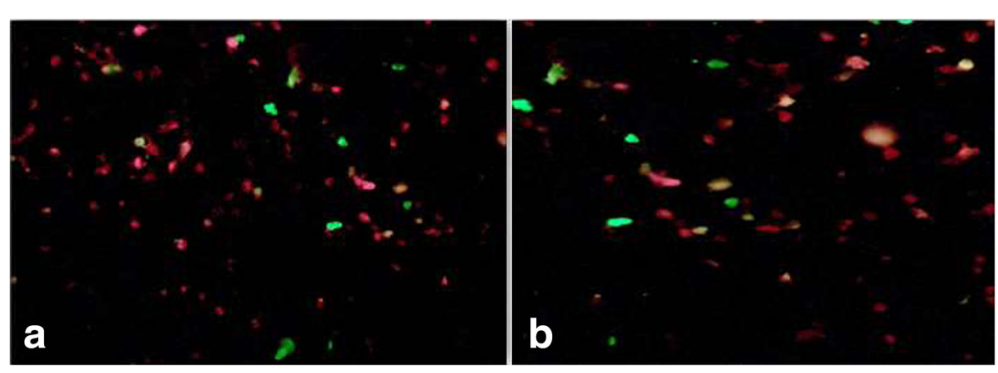

Fig. $\mathbf{3}$ a, b Anaplasma species under fluorescent microscope appears green fluorescent small cocci with a red back ground 
Table 4 Sensitivity and specificity of IFA as compared with gold standard (ELISA and ME) of anaplasma spp.

\begin{tabular}{lllll}
\hline & Gold Standard & & & \\
\cline { 2 - 5 } & & Positive & Negative & Total \\
\hline IFA test & positive & 125 & 11 & 136 \\
& Negative & 0 & 153 & 153 \\
& Total* $^{*}$ & 125 & 164 & 289 \\
\hline
\end{tabular}

* statistically significant $(P$-value is $<0.05)$

${ }^{*}$ statistically highly significant $(P$-value is $<0.01)$

using IFA was 57.4\% (179), of which113 (59.8\%) were sheep and $66(53.7 \%)$ were goats (Table 3$)$. In sheep, the infection rate was higher among males (43.4\%), animals of the age group I (31.7\%), and imported animals (36.5\%). While in goats, the prevalence was $36.6 \%$ among males, $24.4 \%$ among age group I animals, and $34.9 \%$ in imported animals. The agreement between positive and negative results in cELISA and IFA were $82.7 \%$ (148/179). The remainder $17.3 \%$ (31 samples) was represented by samples, which were positive in IFA and negative in cELISA. No samples were found to be negative in IFA but positive in cELISA. The Gold Standard for the detection of Anaplasma spp. is the concordance of both cELISA and microscopic examination results. The sensitivity and specificity of IFA were 100 and 93.3\% respectively, compared with the gold standard (Table 4).

\section{PCR analysis}

Molecular identification of Anaplasma spp. revealed two distinct species: Anaplasma ovis (Fig. 4) and Anaplasma phagocytophilum (Fig. 5). Anaplasma ovis was detected in $25.3 \%$ (25.9\% of sheep and $24.4 \%$ of goats) of the sampled animals, while Anaplasma phagocytophilum was detected in $36.9 \%$ (39.2\% of sheep and $33.3 \%$ of goats). Mixed infections with the two species were detected in $18.9 \%$ of the animals (20.6\% of sheep and $16.3 \%$ of goats).The sensitivity and specificity of PCR assay was 73.2 and $89 \%$ respectively when compared with microscopic examination (Table 5).

\section{Discussion}

Anaplasmosis frequently occurs in tropical and subtropical regions, and it is a major problem to small ruminants [34]. Epidemiologic studies aimed to determine the prevalence of anaplasmosis uses different diagnostic tools, such as microscopic examination of stained blood smears, serological, and molecular tests. The reliability of the diagnostic tests is crucial for accurate diagnosis and estimation of the disease prevalence. Despite microscopic examination and serologic tests are practical and reliable diagnostics to detect Anaplasma spp. infection, they have limitations [1, 47]. The accuracy of stained blood smear examination can be hindered by the low number of infected cells, lack of expertise of the examiner, and/or the occurrence of intracellular artifacts $[2,3]$. In the early acute phase of infection, serologic assays have limited value, due to the absence of detectable antibodies [5, 42].

Our results showed that the number of infected animals by Anaplasma spp. was $43.6 \%$ (45.6\% in sheep and $40.7 \%$ in goats) when examined microscopically compared to $47.4 \%(49.2 \%$ in sheep and $44.7 \%$ in goats) using cELISA and $57.4 \%$ (59.8\% in sheep and $53.7 \%$ in goats) by using IFA. On the other hand, the prevalence using PCR was 62.2\% (65.1\% in sheep and 57.7\% in goats), consistent with previous findings [22]. The variability of infection rates determined by different methods maybe attributed to several factors as, age, gender, and species. Previous studies have shown that some cases of anaplasmosis might be missed depending on the detection method used [30, 33].

In this study, sheep had a higher prevalence of anaplasmosis than goats in agreement with previous studies in India and Cyprus [12, 45]. Based on the age factor, it was found that age group I ( $2 \mathrm{~m}-2 \mathrm{yrs})$ had the highest rate of anaplasmosis. Also, gender seemed to play a role whereby anaplasmosis was more prevalent in males than in females. Additionally, Anaplasma infection rates were higher among the imported sheep and goats compared with local animals. This could be attributed to the presence of a specific tick vector in the source countries.

Anaplasma is routinely diagnosed by microscopic examination of Giemsa stained blood smears and detection of intraerythrocytic Anaplasma inclusions. Microscopic examination is suitable for diagnosis of acute anaplasmosis, but it is not applicable for the detection of pre-symptomatic or

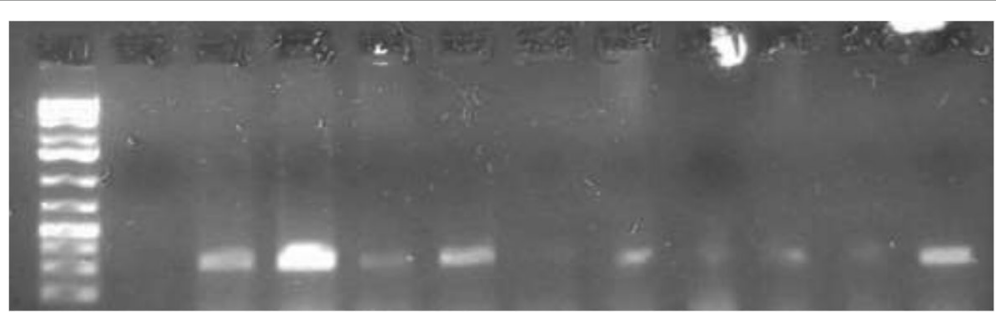

Fig. 4 Agarose gel electrophoreses of PCR products of Anaplasma ovis amplified from DNA purified from sheep and goats blood samples. Right arrowhead indicates position of the $271 \mathrm{bp}$ PCR product 


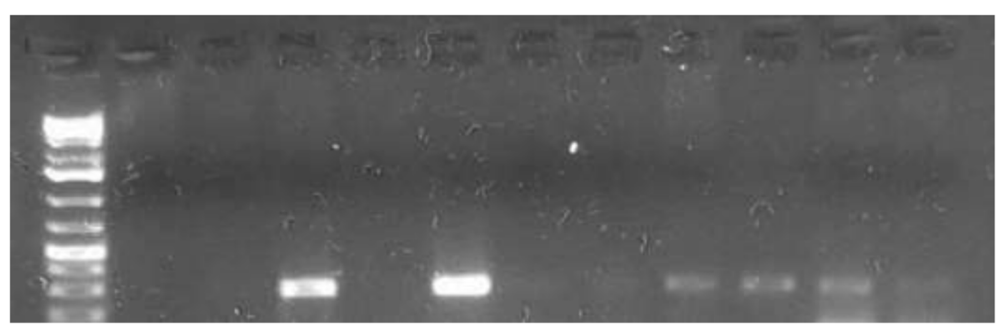

Fig. 5 Agarose gel electrophoreses of PCR products of Anaplasma phagocytophilum amplified from DNA purified from sheep and goats blood samples. Right arrowhead indicates position of the $236 \mathrm{bp} \mathrm{PCR} \mathrm{product}$

carrier cases due to low numbers of Anaplasma infected cells in circulation, which falls below the detection limit $[17,32]$.The cELISA currently used for diagnosis of anaplasmosis is based on the use of ANAF16C1 Mab that recognizes the MSP5 antigen in A. marginale, A. central and A. ovis. The MSP-5 antigen is conserved among all known Anaplasma spp. [15, 16, 29]. Our results showed that cELISA enabled the detection of more Anaplasma cases compared to microscopic examination $(62.2 \%$ vs. $43.6 \%$, respectively), with $91.9 \%$ sensitivity and $86.9 \%$ specificity. This was consistent with the findings of Naqid and Zangana [30] who found that the prevalence of $A$. ovis infection in goats was lower (55.9\%) using Giemsa stained blood smears compared to cELISA (75.2\%).

Indirect fluorescent antibody technique has been recommended and has proven sensitivity for the diagnosis of haemoparasites as Anaplasma spp. [35]. Several studies have reported that IFA may be used as an alternative to PCR, CF, and ELISA [10, 23, 38] for the detection of anaplasmosis among sheep and goats [12, 49]. In this study, we found that IFA had high sensitivity (100\%) and specificity (91.9\%) when compared to the Gold standard (combination of ME and cELISA). A previous study reported a similar level of specificity and sensitivity for IFA when compared with cELISA [22].

Detection of carrier animals is very important, as they play a significant role in the disease epidemiology as reservoirs. Furthermore, it is essential for epidemiologic studies to discriminate between Anaplasma species [31]. PCR is reported to be more sensitive than conventional parasitological techniques in different hosts. It also enables the identification of different species [18, 19]. Therefore, we also evaluated PCR for detection of Anaplasma species in our animals in comparison with ME, cELISA, and IFA.

The sensitivity of the PCR results was 100\% compared to the other diagnostic results. However, in agreement with other studies [30,32], our results revealed that only $70 \%$ of the PCR-positive animals were smear positive. This may be due to animals being examined during the early stage of infection when Anaplasma-infected cells are low. Having the ability to detect and differentiate between Anaplasma species is important for their accurate diagnosis and better understanding of their burden $[11,42]$. Using PCR, we were also able to differentiate between $A$. ovis and A. phagocytophilum and to identify animals with mixed infections. In agreement with other studies, our results revealed that $70 \%$ of PCR-positive animals were smear positive. This may be due to the animals examined in early stage and there is a low number of Anaplasma cells in the circulating blood. Our data and those of others, suggest that PCR may provide a more reliable diagnosis of anaplasmosis particularly during early stages of infection, which would ensure proper management of infected animals and reduction of unnecessary antibiotic use $[4,11]$.

Comparing the sensitivity of the PCR assay with the cELISA, a lower percentage of animals were seropositive than PCR-positive. A previous study on anaplasmosis seroprevalence using cELISA showed that $88 \%$ was seropositive while $76 \%$ were positive by using PCR [22]. In our study, $47.4 \%$ was seropositive while $62.2 \%$ were PCR-positive; which means that $14.8 \%$ of

Table 5 Molecular identification

\begin{tabular}{|c|c|c|c|c|c|c|c|c|}
\hline & \multirow[t]{2}{*}{ Anaplasma spp. } & \multicolumn{2}{|l|}{ Gender } & \multicolumn{3}{|l|}{${ }^{* *}$ Age } & \multicolumn{2}{|l|}{ Source } \\
\hline & & Male & Female & Group I & Group II & Group III & Imported & Local \\
\hline \multirow[t]{2}{*}{ Sheep } & A. ovis & $35(18.5 \%)$ & $14(7.4 \%)$ & $26(13.8 \%)$ & $23(12.2 \%)$ & 0 & 30 (15.9\%) & 19 (10.0\%) \\
\hline & A. phagocytophylum & $50(26.5 \%)$ & $24(12.7 \%)$ & 37 (19.6\%) & $31(16.4 \%)$ & $6(4.8 \%)$ & $38(20.1 \%)$ & $36(19.0 \%)$ \\
\hline \multirow[t]{2}{*}{ Goat } & A. ovis & *19 (60.0\%) & $11(27.6 \%)$ & $13(15.4 \%)$ & $13(15.4 \%)$ & $4(3.3 \%)$ & $16(13.0 \%)$ & $14(11.4 \%)$ \\
\hline & A. phagocytophylum & $20(16.3 \%)$ & $21(17.0 \%)$ & $23(18.7 \%)$ & $16(13.0 \%)$ & $2(1.6 \%)$ & $15(12.2 \%)$ & $26(21.1 \%)$ \\
\hline
\end{tabular}

* statistically significant $(P$-value is $<0.05)$

**statistically highly significant $(P$-value is $<0.01)$ 
PCR-positive sera were seronegative, this may occur in the early stage of infection where antibodies have not yet been produced [5].

The prevalence of $A$. phagocytophylum in sheep was 39 . $2 \%$, and in goats it was $33.3 \%$. While, a lower prevalence of $A$. ovis was reported among sheep and goats, 25.9 and $24.3 \%$, respectively, consistent with previous studies in Cyprus, China, Switzerland, and Italy [12, 37, 44, 49].

The zoonotic potential of $A$. phagocytophilum was previously documented $[36,41]$.The absence of host specificity of $A$. phagocytophilum allows the infection of the human by animal strains and vice versa [6]. Thus, the high prevalence $A$. phagocytophilum detected in the present study constitutes a risk to humans.

\section{Conclusions}

Proper disease diagnosis requires reliable tests. Therefore, it is important to evaluate the existing diagnostic methods. The evaluation depends on several factors as; whether the test is suitable for the field and/or the laboratory settings; cost; and time required. Microscopic examination provides reliable results, but it is not suitable to diagnose carrier animals. cELISA is known for its ease of use, low cost, and for being quantitative. IFA is an economical and easy method to perform. In the present study, IFA was highly specific and sensitive, but it requires special laboratory settings such as fluorescent microscope. PCR is the most sensitive and reliable diagnostic tool that achieves simultaneous differentiation between different Anaplasma subspecies.

\begin{abstract}
Abbreviations
cELISA: Competitive ELISA; CF: Complement fixation tests; ELISA: Enzymelinked immunosorbent assay; IFA: Indirect fluorescence antibody; IgG: Immunoglobulin G; Mab: Monoclonal antibody; ME: Microscopic examination; MSP5: A protein epitope of major surface protein 5; OD: The optical density; PBS: Phosphate-buffer saline; PCR: Polymerase chain reaction
\end{abstract}

\section{Acknowledgements}

We thank Dr. Taha, H.A. for her valuable contributions.

\section{Availability of data and materials}

The datasets used and/or analysed during the current study are available from the corresponding author on reasonable request.

\section{Authors' contributions \\ SIl designed the research, established the experiments scheme, analyzed the data, oriented the statistical results, and wrote the manuscript. ANM, collected the sample, and performed laboratory experiments. ZH contributed to the design and wrote the manuscript with SII. All authors read and approved the final manuscript. \\ Ethics approval and consent to participate \\ This study was approved by the author's institution (Taibah University) and animals owner approval was obtained for collecting the samples.}

\section{Competing interests}

The authors declare that they have no competing interests.

\section{Publisher's Note}

Springer Nature remains neutral with regard to jurisdictional claims in published maps and institutional affiliations.

\section{Author details}

${ }^{1}$ Biology Department, Faculty of Science, Taibah University, Al- madinah Al-munawarah, Saudi Arabia. ${ }^{2}$ Faculty of Veterinary Medicine, Department of Bacteriology, Immunology and Mycology, Suez Canal University, Ismailia, Egypt. ${ }^{3}$ Department of Experimental Pathology, Immunology \& Microbiology, Faculty of Medicine, American University of Beirut, Beirut, Lebanon. ${ }^{4}$ Center for Infectious Diseases Research, Faculty of Medicine, American University of Beirut, Beirut, Lebanon.

Received: 13 February 2018 Accepted: 7 May 2018

Published online: 22 May 2018

\section{References}

1. Aguero-Rosenfeld ME. Diagnosis of human granulocytic ehrlichiosis: state of the art. Vector Borne Zoonotic Dis. 2002;2:233-9.

2. Bakken JS, Aquero-Rosenfeld ME, Tilden RL, Wormser GP, Horowitz HW, Raffalli JT, Baluch M, Riddell D, Walls JJ, Dumler JS. Serial measurements of hematologic counts during the active phase of human granulocytic ehrlichiosis. Clin Infect Dis. 2001;32:862-70.

3. Bakken JS, Dumler JS. Human granulocytic ehrlichiosis. Clin Infect Dis. 2000; 31:554-60.

4. Bakken JS, Dumler JS. Clinical diagnosis and treatment of human granulocytotropic anaplasmosis. Ann N Y Acad Sci. 2006;1078:236-47.

5. Bakken JS, Haller I, Riddell D, Walls JJ, Dumler JS. The serological response of patients infected with the agent of human granulocytic ehrlichiosis. Clin Infect Dis. 2002;34:22-7.

6. Ben Said M, Belkahia H, Alberti A, Zobba R, Bousrih M, Yahiaoui M. Molecular survey of Anaplasma species in small ruminants reveals the presence of novel strains closely related to A. phagocytophilum in Tunisia. Vector Borne Zoonotic Dis. 2015;15(10):580-90.

7. Benjamin MM. Outline of veterinary clinical pathology. III ed. New Delhi: Kalyani Publishers; 2005.

8. Bowmann DD. George's parasitology for veterinarians. 9th ed. Louis: Saunders Elsevier, St; 2009.

9. Bradway DS, Torioni de Echaide S, Knowles DP, Hennager SG, McElwain TF. Sensitivity and specificity of the complement fixation test for detection of cattle persistently infected with Anaplas mamarginale. J Vet Diagn Investig. 2001;13(1):79-81.

10. Centers for Disease Control and Prevention (CDC). Anaplasmosis: statistics and epidemiology. 2016. http://www.cdc.gov/anaplasmosis/stats/. Accessed 2016.

11. Chapman AS, Bakken JS, Folk SM, Paddock CD, Bloch KC, Krusell A, Sexton DJ, Buckingham SC, Marshall GS, Storch GA, Dasch GA, McQuiston JH, Swerdlow DL, Dumler SJ, Nicholson WL, Walker DH, Eremeeva ME, Ohl CA, Tickborne Rickettsial Diseases Working Group, CDC. Diagnosis and management of tickborne rickettsial diseases; 2006.

12. Chochlakis D, loannou I, Sharif L, Kokkini S, Hristophi N, Dimitriou T, Tselentis $Y$, Psaroulaki A. Prevalence of Anaplasma sp. in goats and sheep in Cyprus. Vector Borne Zoonotic Dis. 2009:9(5):457-63.

13. Cohen JF, Korevaar DA, Altman DG, Bruns DE, Gatsonis CA, Hooft L, Irwig L, Levine D, Reitsma JB, de Vet HC, Bossuyt PM. STARD 2015 guidelines for reporting diagnostic accuracy studies: explanation and elaboration. Br Med J Open 2016; 6: 012799.

14. De Kroon JF, NM PÃ, Franssen FF, Uilenberg G. The indirect fluorescent antibody test for bovine anaplasmosis. VetQ. 1990:12(2):124-8.

15. de la Fuente J, Lew A, Lutz H, Meli ML, Hofmann-Lehmann R, Shkap V, Molad T, Mangold AJ, Almazán C, Naranjo V, Gortázar C, Torina A, Caracappa S, García-Pérez AL, Barral M, Oporto B, Ceci L, Carelli G, Blouin EF, Kocan KM. Genetic diversity of Anaplasma species major surface proteins and implications for anaplasmosis serodiagnosis and vaccine development. Anim Health Res Rev. 2005;6:75-89.

16. De la Fuente J, Vicente J, Hofle U, Ruiz-Fons F, Fernández de Mera IG, van den Bussche RA, Kocan KM, Gortazar C. Anaplasma infection in free-ranging Iberian red deer in the region of Castilla-La Mancha Spain. Vet Microbiol. 2004;100:163-73.

17. de Waal T. Advances in diagnosis of protozoan diseases. Vet Parasitol. 2012; 189:65-74. 
18. Desquesnes M, Davila AMR. Application of PCR-based tools for detection and identification of animal trypanosomes; a review and perspectives. Vet Parasitol. 2002;109(3-4):213-33.

19. Dey A, Singh S. Progress of science from microscopy to microarrays (part 1): diagnosis of parasitic diseases. J Lab Phys. 2009;1:2-6.

20. Dumler JS, Barat NC, Barat CE, Bakken JS. Human granulocytic anaplasmosis and macrophage activation. Clin Infect Dis. 2007;45:199-204.

21. Dumler JS, Brouqui P. Molecular diagnosis of human granulocytic anaplasmosis. Expert Rev Mol Diagn. 2004;4:559-69.

22. Ekici OD, Sevinc F. Comparison of CELISA and IFA tests in the serodiagnosis of anaplasmosis in cattle. Afri J Microbiol Res. 2011;5(10):1188-91.

23. Goff WL, Stiller D, Roeder RA, Johnson LW, Falk D, Gorham JR, McGuire TC. Comparison of a DNA probe, complement fixation and indirect immunofluorescence tests for diagnosing Anaplasma marginale in suspected carrier cattle. Vet Microbiol. 1990;24:381-90.

24. Hornok S, Elek V, de la Fuente J, Naranjo V, Farkas R. First serological and molecular evidence on the endemicity of Anaplasma ovis and A. marginale in Hungary. Vet Microbiol. 2007;122(3-4):316-22.

25. Hungerford LL, Smith RD. Variations in seroprevalence and host factors for bovine Anaplasmosis in Illionis. Vet Res Com. 1997;21:9-18.

26. Jonsson NN, Bock RE, Jorgensen WK. Productivity and health effects of anaplasmosis and babesiosis on Bosindicus cattle and their crosses, and the effects of differing intensity of tick control in Australia. Vet Parasitol. 2008; 155(1-2):1-9.

27. Knowles D, Torioni de Echaide S, Palmer G, McGuire T, Stiller D, McElwain T Antibody against an Anaplasma marginale MSP5 epitope common to tick and erythrocyte stages identifies persistently infected cattle. J Clin Microbiol. 1996;34:2225-30

28. Mason KL, Gonzalez MV, Chung C, Mousel MR, White SN, Taylor JB, Scoles GA. Validation of an improved Anaplasma antibody competitive ELISA for detection of Anaplasma ovis antibody in domestic sheep. J Vet Diagn Investig. 2017;29(5):763-6.

29. McElwain TF. Bovine anaplasmosis. In: Manual of standards for diagnostic tests and vaccines for terrestrial animals. Paris office Int. des.Epizoo; 2004. p. 494-506.

30. Nazifi S, Razavi SM, Mansourian M, Nikahval B, Moghaddam M. Studies on correlations among parasitaemia and some hemolytic indices in two tropical diseases (theileriosis and anaplasmosis) in Fars province of Iran. Trop Anim Health Prod. 2008;40:47-53.

31. Niu QL, Luo JX, Guan GQ, Ma ML, Liu ZJ, Liu AH, et al. Detection and differentiation of ovine Theileria and Babesia by reverse line blotting in China. Parasitol Res. 2009;104(6):1417-23.

32. Noaman V, Shayan P. Comparison of microscopy and PCR-RFLP for detection of Anaplasma marginale in carrier cattle. Iran J Microbiol. 2010; 2(2):89-94.

33. Renneker S, Abdo J, Bakheit MA, Kullmann B, Beyer D, Ahmed J. Coinfection of sheep with Anaplasma, Theileria and Babesia species in the Kurdistan region, Iraq. Transbound Emerg Dis. 2013;60(2):113-8.

34. Ros-Garcia A, Barandika JF, Garcia-Perez AL, Juste RA, Hurtado A. Assessment of exposure to piroplasms in sheep grazing in communal mountain pastures by using a multiplex DNA bead-based suspension array. Parasit Vectors. 2013;6(1):277.

35. Salih DA, El Hussein AM, Seitzer U, Ahmed JS. Epidemiological studies on tick-borne diseases of cattle in central Equatoria state, southern Sudan. Parasitol Res. 2007;101(4):1035-44.

36. Scharf W, Schauer S, Freyburger F, Petrovec M, Schaarschmidt-Kiener D, Liebisch G, et al. Distinct host species correlate with Anaplasma phagocytophilum ankA gene clusters. J ClinMicrobiol. 2011;49:790-6.

37. Silaghi C1, Scheuerle MC, Friche Passos LM, Thiel C, Pfister K. PCR detection of Anaplasma phagocytophilum in goat flocks in an area endemic for tickborne fever in Switzerland. Parasite. 2011;18(1):57-62.

38. Silva VMG, Araújo FR, Madruga CR, Soares CO, Kessler RH, Almeida MAO, Fragoso SP, Santos LR, Ramos CAN, Bacanelli G, Torres Júnior RAA. Comparison between indirect enzyme-linked immunosorbent assays for Anaplasma marginale antibodies with recombinant major surface protein 5 and initial body antigens. Mem Inst Oswaldo Cruz, Rio de Janeiro. 2006; 101(5):511-6.

39. Stuen S, Granquist E, Silaghi C. Anaplasma phagocytophilum- a widespread multi-host pathogen with highly adaptive strategies. Front Cell Infect Microbiol. 2013:3:31
40. Stuen S. Anaplasma phagocytophilum - the most widespread tick-borne infection in animals in Europe. Vet Res Commun. 2007:31:79-84.

41. The center of food security and public health2013. http://www.cfsph.iastate. edu/Zoonoses/. Accessed 2013.

42. Thomas RJ, Dumler JS, Carlyon JA. Current management of human granulocytic anaplasmosis, human monocytic ehrlichiosis and Ehrlichia ewingii ehrlichiosis. Expert Rev Anti-Infect Ther. 2009;7:709-22.

43. Torina A, Caracappa S. Tick-borne diseases in sheep and goats: clinical and diagnostic aspects. Small Rumin Res. 2012;106:S6-S11.

44. Torina A, Agnone A, Blanda V, Alongi A, D'Agostino R, Caracappa S, Marino AMF, Di Marco V, de la Fuente J. Development and validation of two PCR tests for the detection of and differentiation between Anaplasma ovis and Anaplasma marginale. Ticks Tick-Borne Dis. 2012;3(5-6):283-7.

45. Velusamy R, Rani N, Ponnudurai G, Anbarasi P. Prevalence of intestinal and haemoprotozoan parasites of small ruminants in Tamil Nadu, India. Vet World. 2015:8(10):1205-9.

46. Visser ES, McGuire TC, Palmer GH, Davis WC, Shkap V, Pipano E, Knowles DP. The Anaplasma marginale msp 5 gene encodes a 19-kilodalton protein conserved in all recognized Anaplasma species. Infect Immun. 1992;60: 5139-44.

47. Woldehiwet Z. The natural history of Anaplasma phagocytophilum. Vet Parasitol. 2010;167(2-4):108-22.

48. Ybañez AP, Sashika M, Inokuma $H$. The phylogenetic position of Anaplasma bovis and inferences on the phylogeny of the genus Anaplasma. J Vet Med Sci. 2014;76:307.

49. Zhang XC, Zhang LX, Li WH, Wang SW, Sun YL, Wang YY, Guan ZZ, Liu XJ, Yang YS, Zhang SG, Yu HL, Zhang L. Ehrlichiosis and zoonotic anaplasmosis in suburban areas of Beijing, China. Vector Borne Zoonotic Dis. 2012;12(11): 932-7.

Ready to submit your research? Choose BMC and benefit from

- fast, convenient online submission

- thorough peer review by experienced researchers in your field

- rapid publication on acceptance

- support for research data, including large and complex data types

- gold Open Access which fosters wider collaboration and increased citations

- maximum visibility for your research: over $100 \mathrm{M}$ website views per year

At BMC, research is always in progress.

Learn more biomedcentral.com/submissions 